\title{
Applied Psychometrics: The 3-Faced Construct Validation Method, a Routine for Evaluating a Factor Structure
}

\author{
Theodoros A. Kyriazos \\ Department of Psychology, Panteion University, Athens, Greece \\ Email: th.kyriazos@gmail.com
}

How to cite this paper: Kyriazos, T. A. (2018). Applied Psychometrics: The 3-Faced Construct Validation Method, a Routine for Evaluating a Factor Structure. Psychology, 9, 2044-2072.

https://doi.org/10.4236/psych.2018.98117

Received: July 11, 2018

Accepted: August 5, 2018

Published: August 8, 2018

Copyright $\odot 2018$ by author and Scientific Research Publishing Inc. This work is licensed under the Creative Commons Attribution International License (CC BY 4.0).

http://creativecommons.org/licenses/by/4.0/

c) (i) Open Access

\begin{abstract}
The " 3 -faced construct validation method" is a routine for establishing the validity and reliability of an existing scale when adapted in a different cultural context from the context initially developed. This routine can also be used for the initial validation of a newly developed scale. This is essentially a construct validation procedure based on a sample-splitting. The sample is randomly split into three parts, $20 \%$ for EFA, $40 \%$ for an exploratory CFA and $40 \%$ for a cross-validating CFA. The cases per variable threshold is set above 5:1, preferably above 10:1 (minimum conditions) and the first approximately 20\% subsample emerges (adequate conditions) to evaluate EFA and Bifactor EFA models. Then the cases per variable threshold is set above 10:1, preferably above 20:1 (minimum conditions) and the $40 \%$ subsample emerges (adequate conditions) to examine alternative CFA models (ICM-CFA, Bifactor CFA, ESEM and Bifactor ESEM models). The optimal model(s) is cross-validated by a second CFA in yet another $40 \%$ subsample (equal-power CFA sample) as a protection against overfitting (over-optimization) to safeguard model replicability. Measurement invariance follows and is essentially another cross-check of the optimal model over the entire sample because the optimal model is used as the baseline model.
\end{abstract}

\section{Keywords}

3-Faced Construct Validation Method, Validity, Reliability, Cross-Validation, Replicability, Overfitting, Over-Optimization, CFA, EFA, Factor Analysis

\section{Introduction}

Each scientific field develops its own methods of measurement. In behavioral sciences, psychometrics is used for quantifying psychological phenomena 
(DeVellis, 2017). However, the replicability of the measurement results is one of the most important criteria of scientific research (Rosenthal \& Rosnow, 1984) in general and in psychometrics more particularly. In quantitative research in psychology, questionnaires are used in the procedure of measurement (DeVellis, 2017). A questionnaire (or psychological test) is a set of standardized self-report statements scored and aggregated to produce a composite score that is an indicator of a phenomenon (Zumbo et al., 2002 quoted in Singh et al., 2016). However, when quantifying psychological phenomena, we often measure aspects of hypothetical constructs, only indirectly observable (Kline, 2009). Thus, questionnaires often measure only indirectly observable constructs. This is a challenge for replicability in behavioral sciences. The second challenge for replicability is the fact that people are idiosyncratic (Thompson, 2013). Moreover, except replicability, it is related to the reliability and validity of measurement instruments. Reliability is defined as the degree to which the scores of a measurement tool are free from random error (Kline, 2009). Validity is related to the soundness of inferences emerging from the scores, i.e. to what extent scores of an instrument measure the construct indenting to measure and not measure a different one, not intending to measure (Thompson \& Vacha-Haase, 2000; Kline, 2009). Reliability is a necessary, but not sufficient condition for validity (Kline, 2013).

A construct, as Nunnally and Bernstein (1994) define it, is a hypothesis, either complete or incomplete, representing a group of correlated behaviors while studying individual differences or/and similarities under by different experimental conditions (p. 85, as reproduced by Kline, 2009). Crocker and Algina (1986) described a construct an "informed scientific imagination" as Sawilowsky (2007) quotes. A latent variable suggests that there is a relationship between a construct and the questionnaire items tapping it. As such it causes changes in the strength or quality of an item (or set of items) and the item(s) take on a certain value. When examining a set of items caused by the same latent variable, we can observe how the items are inter-related (DeVellis, 2017). An item is also called measured variable or indicator and has a unique factor, reflecting systematic variance, not shared with the other measures being analyzed (Russell, 2002; Singh et al., 2016). Hence, categories of similar items are termed latent variables or factors. They are identified with factor analysis, i.e. a method for empirically determining the number of constructs beneath an item set (DeVellis, 2017).

The purpose of the present study is to propose a routine for evaluating the construct validity of measurement instruments, validated in a different cultural context or newly developed using factor analysis. This algorithmic procedure is called "the 3 faced construct validation method."

\section{Why Need a Method?}

In general, construct validity is the central focus of each measurement process (Kline, 2009) and an all-embracing principle of validity (Messick, 1995; Brown, 
2015). Construct validity (Cronbach \& Meehl, 1955) examines the theoretical relationship of a variable (like the scale score) to other variables. It is defined as the extent to which a measuring tool "reacts" the way the construct it purports to react when compared with other, well-known measures of different constructs (DeVellis, 2017). The construct validity incorporates the internal scale structure (Zinbarg, Yovel, Revelle, \& McDonald, 2006; Revelle, 2018) or the correct measurement of variables intended to be examined (Kline, 2009).

However, it is impossible to directly estimate the relationship of an instrument we intend to validate (either new or adapted from another language) and the latent variable. Instead, we do so indirectly, by examining the relationships between the instrument being validated and indicators of the latent variable (Devellis, 2017). Therefore, construct validity is measured only indirectly by indicators (i.e. items). Crucially, there is no single, ultimate test of construct validity. Instead, it is structured and evidenced in multiple studies across time in measurement-based research (Kline, 2009). Thus, Kline (2016) explains, evidencing construct validity requires multiple lines of evidence. The need to cross-validate instruments (questionnaires or ability tests) producing a score on the basis of measured variables (items) is vital to avoid capitalization on chance. To achieve this, whether their values are also observed in different samples is examined evidencing replicability of results (Kline, 2016).

One of the methods to safeguard validity, reliability, and replicability of measurement in psychometrics is cross-validation (Thompson, 1994; Thompson, 2013). During cross-validation (Thompson, 1994; Hill, Thompson \& Williams, 1997), the sample is randomly split into two or more subsamples with the purpose to repeat the intended analysis (in this case factor analysis) in each subsample (Byrne, 2012; Wang \& Wang, 2012; Thompson, 2013; Brown, 2015; Schumacker \& Lomax, 2015). Replicating a factor analytic solution in a different sample is generally considered the preferable method of demonstrating generalizability (DeVellis, 2017). Similar methods to cross-validation are the jackknife and the bootstrapping (Thompson, 2013; Kline, 2013).

In cross-validation, a sufficiently large sample is randomly split into two subsamples. The first sample is called the calibration sample, and the second the validation sample. The purpose of the cross-validating a factor analysis is to examine whether the parameter estimates of the calibration sample can replicate in the validation sample (Byrne, 2012, 2006; Byrne et al., 1989; Wang \& Wang, 2012). The generally suggested way to split a sample is by randomly dividing it into two equal parts. However, when the sample is too small to be halved, it can be split into two unequal parts. The larger subsample can be used for the more crucial process of item evaluation and scale construction and the smaller for cross-validation (DeVellis, 2017; Cudeck \& Browne, 1983; Byrne et al., 1989). The process is equally applicable during scale validation. On sample A (the calibration sample) the hypothesized factor structure is tested, as well as any post hoc analyses for achieving a well-fitting model. Once a viable solution is found, its validity is verified by testing it on sample B (the validation sample) as Byrne 
(2012) describes.

However, a word of caution is suggested in literature because cross-validation does not eliminate the non-replicability due to sample idiosyncrasies, nevertheless, the absence of cross-validation deems idiosyncrasy much more likely (Karson, 2007). In other words, cross-validation is a necessary but insufficient requirement to protect against sample idiosyncrasies. Additionally, two subsamples are probably more similar than two entirely different samples. Despite that, replicating findings by splitting the sample provides valuable information about scale stability (DeVellis, 2017).

The 3-faced construct validation method described in the following section is intended for validating a qualitative measurement instrument in a different cultural context from the one the instrument was initially validated. It is in line with the cross-validation strategy but it contains a complete sequence of phases.

\section{Description of the 3-Faced Construct Validation Method}

The method is about validating a factor structure either of a new instrument or an instrument adaption in a different cultural context from the one of the initial validation. This research aspect is fundamental, especially for cross-cultural research, where the instruments used are assumed to measure the same construct cross-culturally (Milfont \& Fischer, 2010). The method is applied after the data collection has finished and does not cover the translation part of the cultural adaption process of an instrument. More specifically, the method is completed in the following phases:

1) Preliminary phase. The data is screened for missing valued and outliers and the sample is randomly split into three parts. Three subsamples emerge. The first $20 \%$ subsample is used for an EFA, the second $40 \%$ subsample for a CFA and the third $40 \%$ subsample for a second CFA to validate the findings of the previous one in a sample of equal power.

2) The Exploratory Factor Analysis Phase is used to establish a structure (Porter \& Fabrigar, 2007).

3) The first Confirmatory Factor Analysis Phase (CFA 1) is used confirm the EFA structure extracted in the previous phase (Brown, 2015) and to test alternative models (Singh et al., 2016) with multiple different CFA methods. Once EFA analyses have facilitated to establish an empirical basis, more meticulous examination makes use of CFA to carry out more rigorous tests of the factor structure (Porter \& Fabrigar, 2007), as it is generally suggested (Brown, 2015; Muthén \& Muthén, 2009).

4) The second "twin" Confirmatory Factor Analysis Phase (CFA 2) is where the optimal model or competing optimal models are cross-validated in a different CFA subsample of equal power to the CFA 1 subsample.

5) The Measurement Invariance Phase. Finally, the optimal solution becomes the baseline model to examine measurement invariance across gender over the entire sample. 
More specifically, during the preliminary phase, the sample is randomly split into three parts $(20 \%, 40 \%, 40 \%)$. In all three emerging subsamples $(20 \%$ for EFA, $40 \%$ for CFA 1 , and $40 \%$ for CFA 2) the threshold for sample to variable ratio ( $N: \mathrm{p}$ ) is set at as follows: 1 ) at a minimum of 5:1 for EFA (Costello \& Osborne, 2005; Singh et al., 2016), preferably 10:1, and 2) at a minimum of 10:1 for CFA (DeVellis, 2017), ideally 20:1 (Schumacker \& Lomax, 2015). After splitting an EFA is carried-out in the $20 \%$ of the sample to establish a structure (Porter \& Fabrigar, 2007). Then, in the next phase, an exploratory CFA (CFA 1) follows in the second part of the sample (40\%) evaluating multiple models with different CFA methods. Next, the optimal model from the CFA 1 will be replicated in a different subsample of equal power (40\%). This twin CFA (CFA 2) is designed to crosscheck the findings of CFA 1 . A Multigroup CFA in the entire sample finalizes the validation procedure to establish measurement invariance across gender using the optimal model emerging from CFA 2 as a baseline model. If either the CFA 2 or the measurement invariance fails to revalidate the optimal CFA 1 model, then the second best model of the CFA 1 is crosschecked (see Table 1 for an overview of the method).

During the process, multiple methods of exploratory and confirmatory factor analysis are used. In the EFA subsample, an Exploratory Factor Analysis and a Bifactor Exploratory Factor Analysis (Bifactor EFA) are carried out. In the CFA 1 subsample of $40 \%$, CFA methods evaluated include an Independent Cluster Model Confirmatory Factor Analysis (ICM-CFA), a Bifactor Confirmatory Factor Analysis (Bifactor CFA), Exploratory Structural Equation Modeling (ESEM), and a Bifactor Exploratory Structural Equation Modeling (Bifactor ESEM) and a traditional higher-order CFA when applicable. Except for multiple methods, testing multiple alternative factor solutions for the instrument is generally considered a good practice (Reise et al., 2007).

Table 1. Overview of the 3-faced construct validation method.

\begin{tabular}{|c|c|c|c|c|c|}
\hline & Preliminary phase & 1 & 2 & 3 & Finalizing \\
\hline Analysis & $\begin{array}{l}\text { Data is } \\
\text { randomly split } \\
\text { in } 3 \text { parts } \\
(20 \%-40 \%-40 \%)\end{array}$ & EFA & CFA 1 & $\begin{array}{c}\text { CFA } 2 \\
\text { in a sample } \\
\text { of equal power }\end{array}$ & $\begin{array}{l}\text { Measurement } \\
\text { Invariance } \\
\text { across gender }\end{array}$ \\
\hline $\begin{array}{l}\text { Construct } \\
\text { Validity with the } \\
\text { "3-faced construct } \\
\text { validation method" }\end{array}$ & $\begin{array}{c}\text { Data screening \& } \\
\text { Univariate \& } \\
\text { Multivariate Normality }\end{array}$ & $\begin{array}{l}\text { Standard EFA } \\
\text { Bifactor EFA }\end{array}$ & $\begin{array}{c}\text { ICM-CFA } \\
\text { (Single factor, Multifactor) } \\
\text { ESEM } \\
\text { Classic Higher-order CFA } \\
\text { Bifactor CFA Bifactor ESEM }\end{array}$ & $\begin{array}{l}\text { Cross-validation } \\
\text { of optimal } \\
\text { model of step } 2\end{array}$ & $\begin{array}{l}\text { Multi-group } \\
\text { CFA to } \\
\text { establish } \\
\text { Measurement } \\
\text { Invariance }\end{array}$ \\
\hline $\begin{array}{l}\text { Subsample } \\
\text { applied }\end{array}$ & $\begin{array}{l}\text { Planning the } \\
\text { Implementation of } \\
\text { "The 3-faced construct } \\
\text { validation method" }\end{array}$ & EFA SUB-SAMPLE $=20 \%$ & CFA1 SUB-SAMPLE $=40 \%$ & $\begin{array}{c}\text { CFA2 SUB-SAMPLE } \\
=40 \%\end{array}$ & $\begin{array}{l}\text { Entire } \\
\text { Sample }\end{array}$ \\
\hline
\end{tabular}

Note EFA = Exploratory Factor Analysis, ICM-CFA= Independent Cluster Model Confirmatory Factor Analysis, ESEM = Exploratory Structural Equation Modeling. 
Next, the optimal CFA model that will emerge from the CFA $140 \%$ subsample will be cross-validated in a different subsample of equal power to that of CFA 1, i.e. $40 \%$. In this phase, the optimal CFA structure is evaluated further on a different subsample. If alternative competing optimal models emerged, then they all be cross-checked. Then, a multi-group CFA (MGCFA) follows over the entire sample $(20 \%+40 \%+40 \%)$ using the optimal model of the CFA 2 as a baseline model, to test for strict measurement invariance across gender. For the EFA phase the cases-per-variable threshold is set above 5:1, preferably above 10:1 (minimum requirements) to create an approximately $20 \%$ subsample or $1 / 5$ (adequate conditions). In this $1 / 5$ part of the sample EFA and Bifactor EFA models are evaluated. Then for the first CFA phase the minimum conditions are the cases-per-variable threshold to be above 10:1, preferably above 20:1 to create the adequate conditions for the $40 \%$ subsample $(2 / 5)$ to emerge. In this phase alternative CFA models are examined, i.e., ICM-CFA, Bifactor CFA, ESEM and Bifactor ESEM models. For the second CFA phase the optimal model(s) is cross-validated by yet another CFA in a subsample of also $40 \%$. That is an equal-power subsample of $2 / 5$ to keep the minimum and required conditions the same to the ones of the first CFA. This phase is included as a protection against overfitting to safeguard the replicability of the optimal model deriving from the study (see the steps of the method in Table 1 and in Figure 1).

\section{Preliminary Phase}

Generally, applied research (CFA or other) without missing values is considered a luxury because missing data strategies, as a rule, mean loss of statistical

Preliminary phase: Data screening and missing values

- Sample-Splitting (20\% EFA, 40\% CFA 1, 40\% CFA 2)

Phase 1: MLR EFA to Establish a factor structure

- Test alternative models with goodness of fit fit indicators

- Test a Bifactor EFA model

Phase 2: CFA 1 to confirm the factor structure

- Test alternative models (unifator, multifactor correlated or not),

- Test alternative CFA methods (ICM-CFA, ESEM, Bifactor CFA, Bifactor

ESEM, "Tradiitional" Higher Order CFA)

Phase 3: CFA 2 to Cross-check the factor structure with a second CFA of equal power to CFA 1

Cross-validate the optimal model (s) from the previous phase to protect agains overfitting

Finalizing: Measurement Invariance in the entire sample

- The cross-validated model of CFA 2 is the baseline model to test gender invariance

Figure 1. Description of the basic phases of the 3-faced construct validation method. 
power, biased parameter estimates, standard errors, and test statistics (Allison, 2002, 2003; Enders, 2010; Little \& Rubin, 2002; Schafer \& Graham, 2002) as cited by Brown (2015). However, online digital test-batteries offer ways to overcome the problems inherent in missing data and they are freely available, like Google Forms, by Google ${ }^{\oplus}$. One of them is to set the fields of the test battery as required (See the successful implementation of this method in Kyriazos et al., 2018a, 2018b, 2018c). This can reduce or even eliminate the missing values problem (except longitudinal studies where respondents may be missing between different research waves (see Brown, 2015).

\section{Data screening and sample size}

Data screening is an equally important first step because CFA and Structural Equation Modeling, in general, are methods based on correlations, therefore the range of the data values, missing data, outliers, or non-linearity can influence the results (Schumacker \& Lomax, 2015). Outliers and influential cases may be deleted from the data (Muthen \& Muthen, 2012). Additionally, sample size in factor analysis is a heavily debated issue because the replicability of a factor structure is at some extend dependable on the sample size of the analysis and as a rule, a factor solution emerging from a large sample is potentially more reliable than the one from a smaller sample (Devellis, 2017; MacCallum, Widaman, Zhang, \& Hong, 1999). A priori definition of the sample size is suggested to achieve the desired level of statistical power in a CFA or EFA with a given instrument (McQuitty, 2004; Brown, 2015; Singh et al., 2016; Tabachnick \& Fidell, 2013).

A priori or not, both the relative (i.e., to the number of variables analyzed) and the absolute number of cases in the sample is suggested to be considered in factor analysis (DeVellis, 2017; MacCallum et al., 1999) as well as additional parameters pertaining to SEM research in general like the study design (crosssectional vs. longitudinal), model complexity, items reliability, response scale, distribution and parameter estimator (Brown, 2015; Kline, 2016). Many rules of thumb have been proposed about the minimum sample size requirements in factor analysis, e.g., $N \geq 50$ (Pedhazur \& Schmelkin, 1991), $N \geq 100$ (Comrey \& Lee, 1992), $N \geq 200$ (Sivo et al., 2006; Garver \& Menter, 1999; Hoelter, 1983; Hoe, 2008; MacCallum et al., 1999) or $N \geq 300$ (Tabachnick \& Fidell 2013). Comrey and Lee $(1992,1973)$ offer the following guidelines to factor analysis sample size: 100 as poor, 200 as fair, 300 as good, 500 as very good, and 1000 or more as excellent. Nevertheless, Kline (2016) reports a Monte Carlo study (Clark, Miller et al., 2013) elaborating on the difficulty with a "one-size-fits-all" approach to sampling size in factor analysis.

Other suggestions include a minimum number of cases for each free model parameter or the "N:q rule" proposing at least 10 cases per free parameter, or the "N:p rule" suggesting a minimum of 5 to 10 cases per model indicator (Bentler \& Chou, 1987; Ding, Velicer, \& Harlow, 1995; Comrey \& Lee, 1992; Gorsuch, 1983; Anderson \& Gerbing, 1988; Hu, Bentler, \& Kano, 1992), or even 20 cases 
(Costello \& Osborne, 2005; Schumacker \& Lomax, 2015). However, as the sample gets larger, the ratio of cases per indicator can be lowered, therefore Tinsley and Tinsley (1987) proposed a ratio of 5 to 10 cases per item for $N \geq 300$ and a progressively lower ratio for larger sample sizes (DeVellis, 2017).

In brief, in the 3-faced construct validation method, a strategy to eliminate missing data is to use the digital forms to collect data with the fields of the test battery set as required. Data is then suggested to be screened for outliers. Regarding sample power, the "N:p rule" is used with a minimum of 5 cases per indicator in the model for the EFA, ideally 10:1 and a minimum of 10 cases per indicator in the model for CFA, ideally 20:1. Of course, more sophisticated methods also exist to perform power analysis (McCall, 1982; Satorra \& Saris 1985; Jaccard, Jaccard, \& Wan, 1996), including bootstrapping and Monte Carlo, but they are beyond the scope of this work. "Although the relationship of a sample size to the validity of factor analytic solutions is more complex than these rules of thumb indicate, they will probably serve investigators well in most circumstances", as DeVellis (2017: p. 175) concludes.

\section{Sample-Splitting}

Sample splitting is generally used in cross-validate modeling in SEM and is especially recommended for verifying a post hoc CFA model (Byrne, 2012; Brown, 2015; Wang \& Wang, 2012; Kline, 2015) or when testing a new instrument (DeVellis, 2017). A general suggestion is to halve the sample when the size is large enough to accommodate it (Byrne, 2012; Wang \& Wang 2012) or to divide it in two unequal parts when the size is smaller using the larger subsample for a calibration or construction sample and the second as validation sample (DeVellis, 2017). One additional recommended method of sample splitting is into one-third and two-thirds (Guadagnoli \& Velicer 1988; MacCallum et al. 1996). Singh et al. (2016) abide by this method and they suggest an EFA be carried out in one-third data, and a CFA on two-thirds of the data as SEM requires large samples (Kline, 2016). The factor structure emerges as they suggest form the final list of domains and items (Singh et al., 2016).

In the 3 -faced construct validation method, the sample is randomly split into three subsamples, $20 \%, 40 \%$ and $40 \%$. The first $20 \%$ subsample is used for an EFA, the second $40 \%$ subsample for a CFA and the third $40 \%$ subsample for an additional "twin" CFA, i.e. a CFA where the findings of the previous CFA are cross-checked in a sample of equal power. Caution is taken to keep the sample to model indicators ratio $>5$ in the $20 \%$ EFA sample (minimum condition and adequate condition respectively) and $>10$ in the "twin" $40 \%$ CFA samples ( $>10$ is again the minimum condition and $40 \%$ is the adequate condition). However, to end up inadequately powerful subsamples, the initial sample must be large enough and this is an issue addressed during the planning of the study. This is not feasible in special population studies and when studying certain the constructs, like flow (Csikszentmihalyi, 2000) that require special data collection processes (e.g. ESM; Csikszentmihalyi, Larson, \& Prescott, 1977). 
Note that sample sizes in absolute numbers are only a rough guide, to indicated the logic pertaining the method, what is of greater importance when splitting a sample is to maintain the N:p ratios above the threshold of 5:1 for EFA and 10:1 for CFA. However, what to keep in mind is not the exact percentage to split a sample. Instead, what to keep in mind is that when the cases to indicators ratios are at the specified levels the minimum conditions are met. Then the sample can be divided into five parts and the adequate conditions will have been met too. One part can be used for the EFA and the four parts for the two CFAs (2 parts for each). This would result in a sample $\mathrm{x}$ for EFA and 2x for each CFA as SEM requires large samples.

Next, the assumption of normality is examined in all four samples emerging after splitting, i.e. Total, EFA (20\%), CFA 1 (40\%), CFA 2 (40\%), see Table 2. The assumption of univariate normality is evaluated first using Kolmogorov-Smirnov tests (Massey, 1951) on each of the indicators. Then, multivariate normality is examined by the following four tests: 1) Mardia's multivariate kurtosis test (Mardia, 1970); 2) Mardia's multivariate skewness test (Mardia, 1970); 3) Henze-Zirkler's consistent test (Henze \& Zirkler, 1990), and 4) Doornik-Hansen omnibus test (Doornik \& Hansen, 2008). A multivariate normal distribution denotes that the univariate and bivariate normality assumption is also not violated (Hayduk, 1987; Wang \& Wang, 2012). See an overview of this phase in Figure 2.

Phase 1: Establishing a factor structure with Exploratory Factor Analysis (EFA)

Exploratory factor Analysis (Spearman, 1904; Spearman, 1927) adopts the premises of the common factor model (Thurstone, 1935, 1947). EFA is used to explore the dimensionality of a measurement instrument (e.g. questionnaire or ability test) by defining a minimum set of factors required to interpret the correlations among a set of variables. It is exploratory because it only specifies the number of latent factors without defining an a priori structure on the linear relationships between the observed variables and the latent factors (Muthén \&

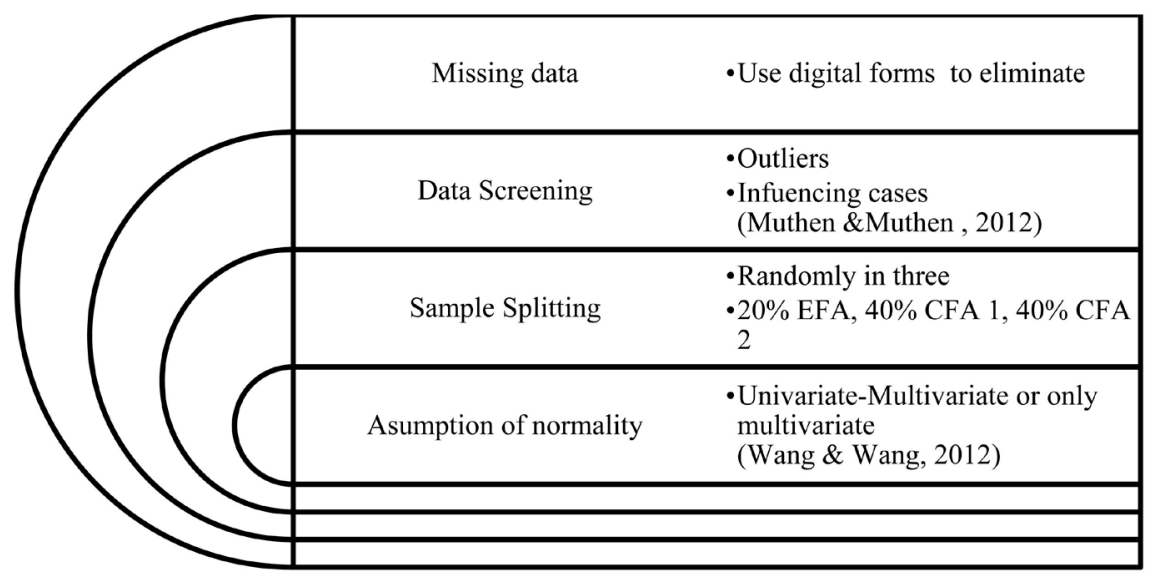

Figure 2. Description of the Preliminary Phase of the 3-faced construct validation method. 
Table 2. Rules for splitting the sample in three pats in the 3-faced construct validation method.

\begin{tabular}{|c|c|}
\hline Subsample & Sample Splitting Rule \\
\hline EFA $(20 \%)$ & $\begin{array}{c}\text { Keep the N:p ratio at a minimum }>5: 1 \text { and preferably }>10: 1 \\
(\text { minimum conditions) then use about } 20 \% \text { for EFA } \\
(1 / 5 \text {; adequate conditions })\end{array}$ \\
\hline $\begin{array}{c}\text { Calibrating } \\
\text { CFA } 1(40 \%)\end{array}$ & $\begin{array}{c}\text { Keep the N:p ratio at a minimum }>10: 1 \text { and preferably }>20: 1 \\
\text { (minimum conditions)then use about } 40 \% \text { for CFA } \\
(2 / 5 \text {; adequate conditions })\end{array}$ \\
\hline $\begin{array}{l}\text { Validating } \\
\text { CFA } 2(40 \%)\end{array}$ & $\begin{array}{c}\text { Keep the } \mathrm{N} \text { :p ratio at a minimum }>10: 1 \text { and preferably }>20: 1 \\
\text { (minimum conditions) then use about } 40 \% \text { for CFA } \\
(2 / 5 \text {; adequate conditions })\end{array}$ \\
\hline
\end{tabular}

Muthén, 2009a). This set of underlying variables discovered is the factor solution, which constitutes the construct being measured (Sawilowsky, 2007). Five basic questions emerge during the EFA process: 1) Is the data suitable for factor analysis? 2) How will the factors be extracted? 3) What criteria will assist in determining factor extraction? 4) What rotational method will be used? 5) is the factor solution interpret table? (Williams et al., 2010). Therefore, it is considered an indeterminate solution because there are a plethora of available choices making the method rather heuristic (Sawilowsky, 2007; Costello \& Osborne, 2005; Williams, Brown, \& Onsman, 2010; Brown, 2015; Thompson, 2004; Tabachnick and Fidell, 2013). Note that in this work EFA is differentiated from Principal Components Analysis (Costello \& Osborne, 2005; Fabrigar \& Wegener, 2012; Brown, 2015 to name a few).

Conventionally, EFA is considered an exploratory method used in absence of a priori assumptions about factor structure and CFA methods are based on a priori assumptions about the factor structure of a scale (Williams et al., 2010; Fabrigar \& Wegener, 2012; Kahn, 2006; Preacher, MacCallum et al., 2003; Howard et al., 2016). The fundamental difference between EFA and CFA is that in the former all cross-loadings are freely estimated while in CFA (more precisely in the Independent Cluster Model CFA or ICM-CFA; see Morin et al., 2014) by default all cross-loadings are constrained to be zero. The free estimation of cross-loadings renders EFA more explorative than CFA (Morin et al., 2013: p. 396; Howard et al., 2016). On the other hand, a presumed advantage of CFA in comparison to EFA is the specific goodness of fit criteria with the calculation of model fit indices.

Nonetheless, when EFA is carried out with estimators used also in CFA the same goodness of fit indicators can be calculated. Such estimators include the maximum likelihood parameter estimate (ML), or the Robust maximum likelihood estimation (MLR, Muthen \& Muthen, 2012 or MLM; Bentler, 1995) that are robust to non-normality. Additionally, MLR is appropriate for medium to small samples (Bentler \& Yuan, 1999; Muthen \& Asparouhov, 2002; Wang \& Wang, 2012) like those emerging after sample-splitting. The MLR estimator is a 
corrected normal theory method with robust standard errors and corrected model test statistics (Wang \& Wang, 2012; Savalei, 2014; Kline, 2016; Brown, 2015). Actually, MLR (or ML or MLM) EFA is considered as a special case of SEM (Brown, 2015). Like in CFA and SEM, in MLR EFA goodness-of-fit information is available to determine the appropriate number of factors (such as chi-square and the root mean square error of approximation, or RMSEA; Steiger \& Lind, 1980).

During the EFA phase of the of the 3-faced construct validation method, an MLR EFA is carried out in the first $20 \%$ subsample taking into account the above-mentioned properties of MLR. The factor rotation used is the oblique rotation of GEOMIN (see Muthen \& Muthen, 2012). As a rule, an oblique rotation is preferable in social sciences because it is considered a more realistic representation of factors interrelations. As Brown (2015) comments if the factors are actually uncorrelated, the oblique rotation will offer a model identical to the orthogonal rotation model. On the other hand, if the factors are interrelated, an oblique rotation will offer a more accurate representation of the magnitude of the factor relationships along with important information like redundant factors or a potential higher-order structure. Moreover, when EFA is used in cohort with a subsequent CFA, like in this case, oblique solutions are more likely interpretable to CFA models than orthogonal solutions, because uncorrelated factors tend to have poor model fit (Brown, 2015).

Additionally, MLR (or ML) EFA facilitates estimation of multiple models testing different numbers of factors to compare model fit, in tandem with other criteria (Brown, 2015) like theoretical background of the solution, cross-loadings, poorly defined factors and number of items per factor (Fabrigar et al. 1999; Gorsuch 1983; Russell 2002; Fabrigar \& Wegener, 2012; Costello \& Osborne, 2005). Thus, multiple EFA models are generally tested in the MLR EFA subsample (20\% of $N$ with an N/p threshold of 5:1, preferably 10:1). MLR EFA is performed to establish a factor structure (Porter \& Fabrigar, 2007) testing alternative models with 1-3 or more factors. Second, an EFA Bifactor model (Jennrich \& Bentler, 2011) is tested subsequently when applicable $(m>1$; Muthen \& $\mathrm{Mu}-$ then, 2012). Reise et al. (2007) suggested that the evaluation of a Bifactor model is a good practice when establishing construct dimensionality (c.f. Hammer \& Toland, 2016). See MLR EFA process in Figure 3.

Specifically, Bifactor analysis is a form of confirmatory factor analysis originally introduced by Holzinger (1937). The bifactor model has a general factor and a set of specific factors (Brown, 2015). An advantage of EFA bi-factor analysis is that an a priori model is not necessary. The results of an EFA bifactor analysis, however, can be used as a basis for defining a CFA Bifactor model (Howard et al., 2016). The EFA Bifactor factor analysis (Jennrich \& Bentler, 2011, 2012) in the 3-faced construct validation method is carried out using also MLR to estimate model parameters and a BI-GEOMIN factor rotation (Jennrich \& Bentler, 2011, 2012), as a rule. The BI-GEOMIN is an oblique rotation where the specific factors are 


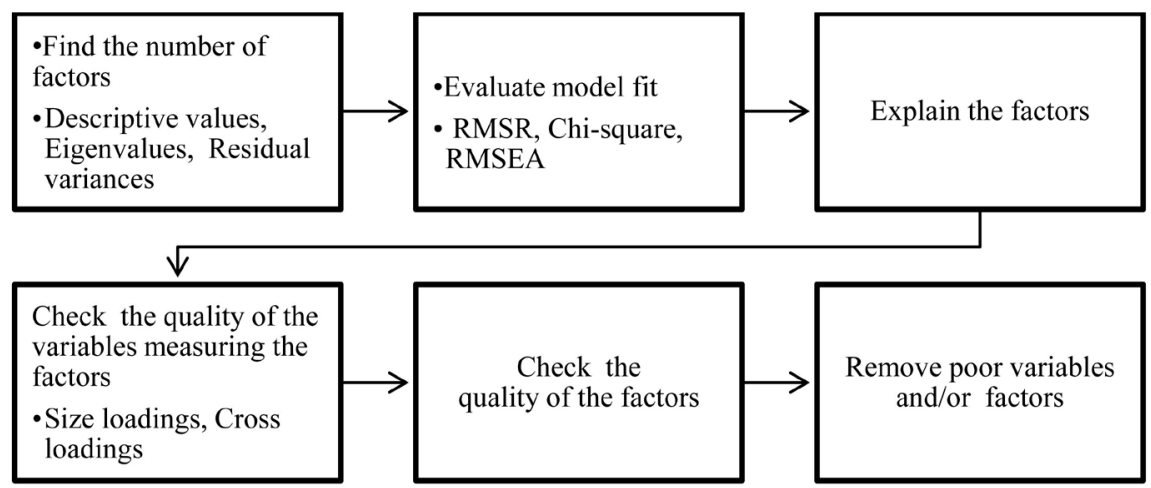

Figure 3. MLR EFA Steps as described by Muthén \& Muthén (2009b).

correlated with both the general factor and with each other. If the orthogonal rotation is used, then the specific factors are uncorrelated both with the general factor and with each other (Muthen \& Muthen, 2012). However, a word of caution is required because Bifactor models always tend to support unidimensionality (Joshanloo, Jose, \& Kielpikowski, 2017) and higher order factor structure based only on a Bifactor model is often regarded questionable (Joshanloo \& Jovanovic, 2017).

MLR EFA model fit is evaluated by the following criteria (Hu \& Bentler, 1999; Brown, 2015): RMSEA ( $\leq .06,90 \% \mathrm{CI} \leq .06)$, SRMR ( $\leq .08)$, CFI $(\geq .95)$, TLI $(\geq .95)$, and the chi-square/df ratio less than 3 (Kline, 2016). See the EFA phase in Figure 4.

Like already said, EFA is an exploratory process, therefore, EFA results are generally with additional CFAs on a different data set (Cudeck, MacCallum et al., 2007; Bollen, 2002; Brown, 2015; Schumacker \& Lomax, 2015). CFA is the subsequent phase of the 3 -faced construct validation method.

Phase 2: Confirming the factor structure with Confirmatory Factor Analysis (CFA)

CFA is integrated into the Structural Equation Modeling (SEM) framework. SEM comprises models in which regressions among continuous latent variables are estimated (Bollen, 1989; Browne \& Arminger, 1995; Joreskog, Sorbom, \& Magidson, 1979; Muthen \& Muthen, 2012). Thus a CFA model construction follows the same steps as an SEM model: 1) Model specification. Theory and prior research play an important role in a CFA model specification because it is based on previous research and knowledge. 2) Model identification. In CFA a model is identified by constraining some parameters and freely estimating others. 3) Model estimation. Estimating the fit of the free parameters of the specified factor model. 4) Testing model fit 5) Model modification. Changes to a specified model are considered when the specified model is less than satisfactory (Kelloway, 2015; Schumacker \& Lomax, 2015).

During this phase of the 3-faced construct validation method the factor structure established in the MLR EFA subsample (20\% of $N$ with a N:p threshold of 5:1, preferably 10:1) it is confirmed with an CFA ( $40 \%$ of $N$ with a N:p threshold 


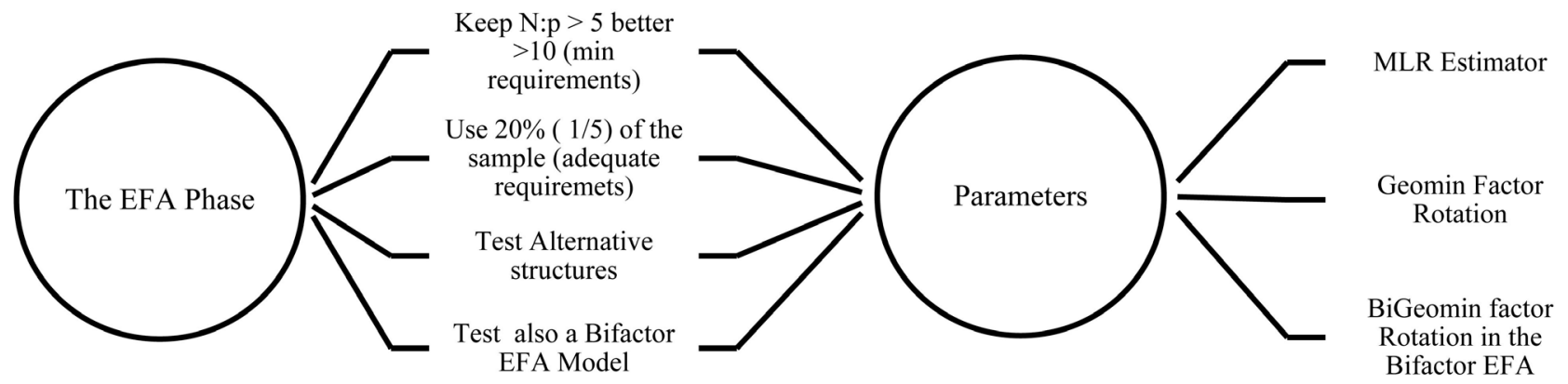

Figure 4. Description of the EFA Phase of the 3-faced construct validation method.

of 10:1, preferably 20:1). This is accomplished by testing alternative models with multiple CFA methods. CFA methods used in the 3-faced construct validation method are the following: 1) Independent Cluster Model Confirmatory Factor Analysis (ICM-CFA), 2) Exploratory Structural Equation Modeling Analysis (ESEM), 3) Bifactor Confirmatory Factor Analysis (Bifactor CFA), and 4) Bifactor Exploratory Structural Equation Modeling Analysis (Bifactor ESEM), 5) Higher order CFA (when applicable).

In ICM-CFA is the basic Independent Clusters Model of Confirmatory Factor Analysis that posits all items have zero factor loadings on all other factors except the one they are intended to measure (McDonald, 1985; Morin et al., 2016; Howard et al., 2016). Even trivial cross-loadings when constrained to be zero results in inflated CFA factor correlations (Asparouhov \& Muthén, 2009; Marsh et al. 2009, 2010). ESEM (Asparouhov \& Muthén, 2009) is an integration of CFA and EFA. In EFA all cross-loadings are freely estimated and in ESEM a specific percentage of cross-loadings are allowed to be freely estimated (Muthen \& Mithen, 2012). This potentially resolves the factor inflation problem inherent in ICM-CFA, especially pertinent in psychology research where constructs generally tend to be correlated (Marsh, Morin, Parker \& Kaur, 2014). As a rule, ESEM potentially produces more accurate models in comparison to ICM-CFA (Howard, Gagne, Morin, Wang \& Forest, 2016). Therefore, testing ESEM models (when $m>1$ ) is generally regarded as a good practice when testing dimensionality of an instrument.

In the 3-faced construct validation method the CFA methods is suggested to test the higher order factor structure are the following: 1) Bifactor Models: Bifactor CFA, Bifactor ESEM; and 2) Second-order CFA. Bifactor analysis (Harman, 1976; Holzinger \& Swineford, 1937) is another approach to higher-order factor analysis, specifying direct effects of the higher-order dimension (General factor) on the indicators (Specific factors), unlike the classical higher-order CFA method. The benefit of the exploratory Bifactor analysis method is that a specific a priori bi-factor model is not necessary. In Bifactor ESEM (c.f. Reise, 2012; Marsh et al., 2014) direct effects of the higher-order dimension are specified and additionally because ESEM (Asparouhov \& Muthén, 2009) can potentially resolve misspecifications and inflated factor loadings, inherent in CFA method as a result of forcing secondary factor loadings to be equal to zero (Marsh et al., 
2014). Concerning the theoretical construct behind the Bifactor higher order structure, bifactor models are most appropriate for unidimensional constructs, having at the same time smaller latent sub-factors (Brown, 2015). Actually, Reise et al. (2007) recommended testing a bifactor model when examining dimensionality. The traditional higher order factor analysis is typically carried out because occasionally first-order factors indicate narrow-scope constructs, interconnected with a higher and broader construct represented in factor analysis by one or more higher order factors (Cattell, 1978; Comrey, 1988; Gorsuch, 1983 cited in Wolff \& Preising, 2005). Thus, higher-order CFA (most of the times second-order) is a theory-based solution with an additional, more parsimonious higher structure that represents the latent factor interrelationships established in the CFA (Brown, 2015; Wang \& Wang, 2012).

Alternative models evaluated in the 3-faced construct validation method are the following: 1) a Unidimensional model to test the assumption of maximum parsimony (Brown, 2015; Crawford \& Henry, 2004); 2) Uncorrelated factors model; or/and 3) Correlated factors model(s) based on theory and previous empirical research (Schumacker \& Lomax, 2015); 4) Second-order factor models are tested if possible. Specifically, when first-order factors $>3$, evaluating if the second-order factor improves the model fit when compared to the first-order solution is not possible because of under-identification of the higher order model (Wang \& Wang, 2012); and 5) Bifactor models (CFA and ESEM) are tested if applicable, i.e. if $m>1$ (Muthen \& Muthen, 2012), suggested by Reise et al. (2007) to be a good practice (also by Hammer \& Tolland, 2016). See all CFA 1 methods tested in Table 3.

Regarding model parametrization (see also Figure 5) in the 3-faced construct validation method MLR is generally suggested as a parameter estimator for all CFA models evaluated, like in EFA for reason. Model fit is estimated by the following criteria (Hu \& Bentler, 1999; Brown, 2015): RMSEA ( $\leq .06,90 \% \mathrm{CI} \leq .06)$, SRMR ( $\leq .08)$, CFI $(\geq .95)$, TLI $(\geq .95)$, and the chi-square/df ratio less than 3 (Kline, 2016). There are abundant indicators of goodness-of-fit, both absolute and incremental (Singh et al., 2016), and researchers are generally urged evaluating model fit by taking into consideration multiple fit indicators to have more conservative model fit estimation (Bentler \& Wu, 2002; Hair et al., 2010; Brown, 2015; Kline, 2016). A second CFA in a sample of equal power to the first $\mathrm{CFA}$ is the next phase of the 3 -faced construct validation method.

Table 3. CFA methods included in the 3 -faced construct validation method and models tested per method.

\begin{tabular}{cc}
\hline 1$)$ & ICM-CFA models : Single-factor, Multifactor (Correlated/Uncorrelated) \\
& ESEM models: Multifactor $(m>1)$ \\
2) & Bifactor CFA Models: Multifactor correlated $(m>1)$ \\
3) & Sifactor ESEM models: Multifactor correlated $(m>1)$ \\
\hline
\end{tabular}

Note. $m=$ number of latent variables, EFA = Exploratory Factor Analysis, ICM-CFA = Independent Cluster Model Confirmatory Factor Analysis, ESEM = Exploratory Structural Equation Modeling. 


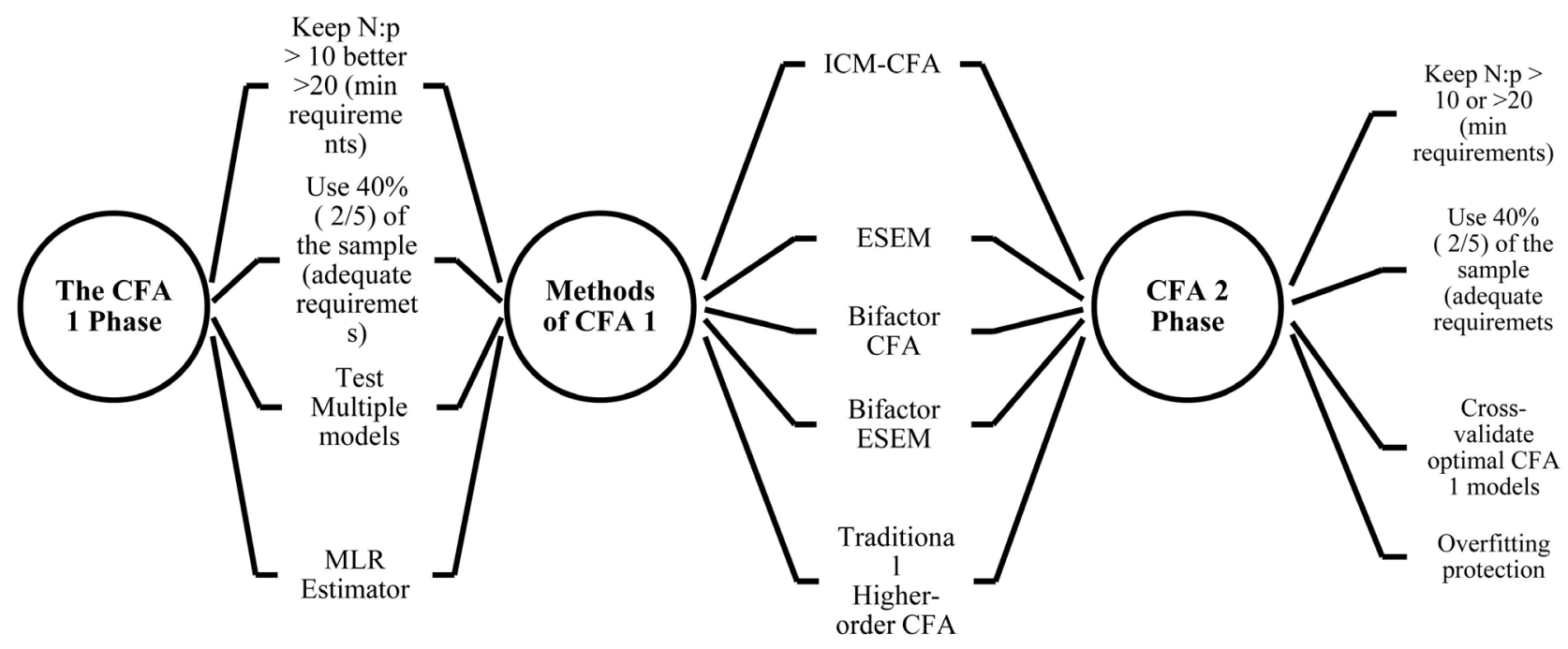

Figure 5. Description of the CFA 1 Phase and CFA2 Phase of the 3-faced construct validation method.

Phase 3: Cross-checking the factor structure with a second Confirmatory Factor Analysis (CFA)

In the realm of SEM, the cross-validation method of testing replicability (see the section "Why need a Method?") is called cross-validation modeling (Wang \& Wang, 2012). A cross-validation CFA is the $3^{\text {rd }}$ phase of the 3 -faced construct validation method (see Figure 5). During this phase the optimal model(s) emerging from the initial CFA of the previous phase (implemented on $40 \%$ of $N$ with a $\mathrm{N}: \mathrm{p}$ threshold of 10:1, preferably 20:1) are replicated on a new subsample that has the same sample power to the initial CFA subsample, i.e. in the $40 \%$ of $N$ with a N:p threshold of 10:1, preferably 20:1). Cross-validation is a persuasive strategy for addressing the implications of post hoc modeling and the potential over-optimization inherently connected with post hoc model modification but also partial invariance (Byrne, 2012; Wang \& Wang 2012).

In this phase, the optimal models emerging from this phase are compared to each other. An additional model comparison is carried out using the following guidelines: 1) a likelihood ratio test, 2) information criteria and 3) modification indices. The models are considered superior they have: 1) a lower Akaike Information Criterion (AIC), 2) a lower Bayesian information criterion (BIC) 3) If models significantly differ, the more complicated model is preferable, 4e) If models do not significantly differ, the less complicated model is preferable (Epskamp et al., 2017). To compare the fit of the optimal solutions with alternative choices to the ML estimator for non-normal data (like MLR) the MLR rescaled version of the "likelihood ratio test" (2ALL; Satorra \& Bentler, 2010) is calculated and if it is statistically significant, the equal factor variance hypothesis can be rejected (Wang \& Wang, 2012). This essentially suggests that there is a fit difference between the optimal CFA models.

It is generally suggested by the 3-faced construct validation method to cross-validate a group of optimal models with the comparable goodness of fit 
and not just the best fitting solution because often a local optimum fitting model emerges, showing a divergence in fit during the two CFAs. Additionally, this is a protection against over-fitting due to post hoc model revision to achieve a better fit that most often is not replicable in the validation subsample. Overfittingspecifying unnecessary parameters to the model to improve fit-is generally regarded as a consequence of non-theory-driven specification searches daring model modification and capitalization on chance (Brown, 2015). This means that weak effects in the data-set are targeted emerging mainly from sampling error, thus are non-replicable in a different data-set (MacCallum, Roznowski, \& Necowitz, 1992; MacCallum, 1986; Silvia \& MacCallum, 1988; Byrne, 2012; Kline, 2016; Brown, 2015). Cross-validating a post-hoc model in a new subsample generally suggests that the likelihood of non-replicability is lower in comparison to a non-cross-validated sample but not minimal. In other words, cross-validation is a necessary but insufficient requirement to protect against non-replicability due to sample idiosyncrasies (Karson, 2007). Additionally, there is always the chance a good fitting model to be non-replicable in the second sample. Then the researcher should choose a different model that is more stable across all three subsamples (EFA, 20\%, CFA $140 \%$ and CFA $240 \%$ ) and not necessarily the model of the best fit. There are some examples for applying this method (Kyriazos et al., 2018a, 2018b, 2018c, 2018d) where such a case emerged (Kyriazos et al, 2018e).

Generally, the post hoc model fitting has been heavily debated in SEM and CFA literature regarding Type I errors (Byrne, 2012; Brown, 2015) and it is a strategy mainly recommended for minimizing implications resulting from post hoc model fitting (Wang \& Wang, 2012). It is generally suggested that the final model of a post hoc analysis to be tested on a second (or more) independent sample(s) from the same population (see also Byrne, 2012; Byrne, 2006). Several other approaches were also proposed as a remedy (e.g. Green \& Babyak, 1997; Green, Thompson, \& Poirier, 2001; Chou \& Bentler, 1990; Green, Thompson, \& Poirier, 1999) as Byrne (2012) reviews. The last remedy to the problem of chance factors-as Byrne (2012) continues-is to cross-validate the final post hoc modified model in a different sample either new or subsample with sample-splitting (see also Thompson, 2000 and MacCallum and Austin, 2000).

Byrne et al. (1989), as reported by Wang \& Wang (2012), also raised certain practical issues regarding cross-validation. The most important of them is the accessibility to a sufficiently large sample to be split, and the possibility of failure of the cross-validation when multiple parameters are relaxed in the first sample (Wang \& Wang 2012). Some other experts also questioned the method (Cliff, 1983; Cudeck \& Browne, 1983) while others (Byrne et al., 1989, Byrne, 2012, Byrne, 2006) suggest that as long as the researcher keeps in mind the exploratory nature of the CFA cross-validation analysis, the cross-validation process is useful (Byrne, 2011; MacCallum, Roznowski, Mar, \& Reith, 1994; MacCallum, Wegener, Uchino, \& Fabrigar, 1993). Above all, CFA researchers are aware of the 
exploratory nature of the post hoc procedures if not theoretically substantiated (Byrne, 2012).

Finalizing: Measurement invariance of the cross-validated optimal CFA model

In the final phase of the 3-faced construct validation method measurement invariance of the instrument is examined across gender in the entire sample $(100 \%$ of $N)$. Generally, measurement invariance examines if an instrument exhibits the same psychometric properties across heterogeneous groups (Chen, 2007) or across time (Brown, 2015). When doing multiple-group confirmatory factor analysis, this assumption can be tested directly (Timmons, 2010).

To test for measurement invariance across gender groups in the 3-faced construct validation method the optimal model, successfully cross-validated in the second CFA, is used as a baseline model. First, gender invariance of the successfully cross-validated model is tested separately in each gender group, to establish a baseline model. This model should show an equally good fit for both gender groups. Then, this baseline solution is tested in both gender groups simultaneously and if the fit is adequate configural invariance is supported (Horn, McArdle, \& Mason, 1983). The chi-square, RMSEA, CFI, and other fit indexes are used to determine whether the combined model has a good model fit to support configural invariance. Next, factor loadings, indicator intercepts, and indicator residuals are consecutively constrained to equality. The $\triangle \mathrm{CFI}$ and $\triangle$ RMSEA for the constrained models are evaluated to indicate weak, strong and strict invariance respectively the ultimate test of measurement invariance (Wang $\&$ Wang, 2012). The criteria used are the $\Delta \mathrm{CFI} \leq-.01$, and $\triangle \mathrm{RMSEA} \leq .015$ for $N>300$ (Chen, 2007: p. 501). Suggested criteria in the literature are also defined by Cheung \& Rensvold (2002).

Alternatively, if the sample is not sufficient (e.g. $N=150$ ) measurement invariance can be omitted and population heterogeneity and measurement invariance can be evaluated for latent means and item intercepts with the Multiple Indicators Multiple Causes method (MIMIC) controlling for the effects of gender or age. Multiple Indicators Multiple Causes Modeling (MIMIC) or CFA with covariates is an alternative method for examining invariance of indicators and latent means in multiple groups, by regressing them onto covariates indicating group membership (Muthén \& Muthén, 2009a). Crucially, MIMIC models are more appropriate for small samples (even of $N=150$ ) than multiple-group CFA (Brown, 2015: pp. 273-274). Initially, a viable measurement model is necessary, collapsing across specified groups (i.e., a typical CFA model). For this purpose, in the 3-faced construct validation method the optimal model that was successfully cross-validated in the second CFA is used in the full sample $(100 \%$ of $N)$. Then, as a rule, the covariates of gender and age are added to examine their direct effects on the factor(s) and selected indicators of the model, i.e. the regression of a factor indicator on a covariate in order to study population heterogeneity and measurement non-invariance respectively (Muthen \& Muthen, 2012; Brown, 2015). Unlike multiple-groups CFA, MIMIC models test only if there is 
invariance in the indicator intercepts and factor means, assuming that all other measurements and structural levels of invariance (i.e., equal factor loadings, error variances/covariances, factor variances/covariances) are supported same across covariates (Brown, 2015).

Remember that to establish measurement invariance in the 3-faced construct validation method the optimal model that was successfully cross-checked in the second CFA ( $40 \%$ of the sample) is tested over the entire sample to become a baseline model, thus, in essence, this is yet another cross-validation of the optimal model emerged from the whole process. Note also that measurement invariance can be evaluated in higher levels, like variance and covariance invariance (Widaman \& Reise, 1997). However, configural, factor loading, indicator intercepts, and indicator residuals invariance are the most invariance tests carried out in the majority of the studies (Chen, 2007).

\section{Method Summary and Applicability}

To establish the construct validity of an instrument designed for a different cultural context we developed a multiphase cross-validation procedure called the "3-faced construct validation method" (see method phases in Figure 6). Note that this method does not cover the translation phase but the subsequent stages. The method is based on sample-splitting. Sample-splitting (Guadagnoli \& Velicer, 1988; MacCallum, Browne, \& Sugawara, 1996) is generally regarded as a cross-validation method because factor analysis findings are replicated in a different subsample (Byrne, 2012; Brown, 2015; Schumacker \& Lomax, 2015; Singh et al., 2016; DeVellis, 2017). In the "3-faced construct validation method" the
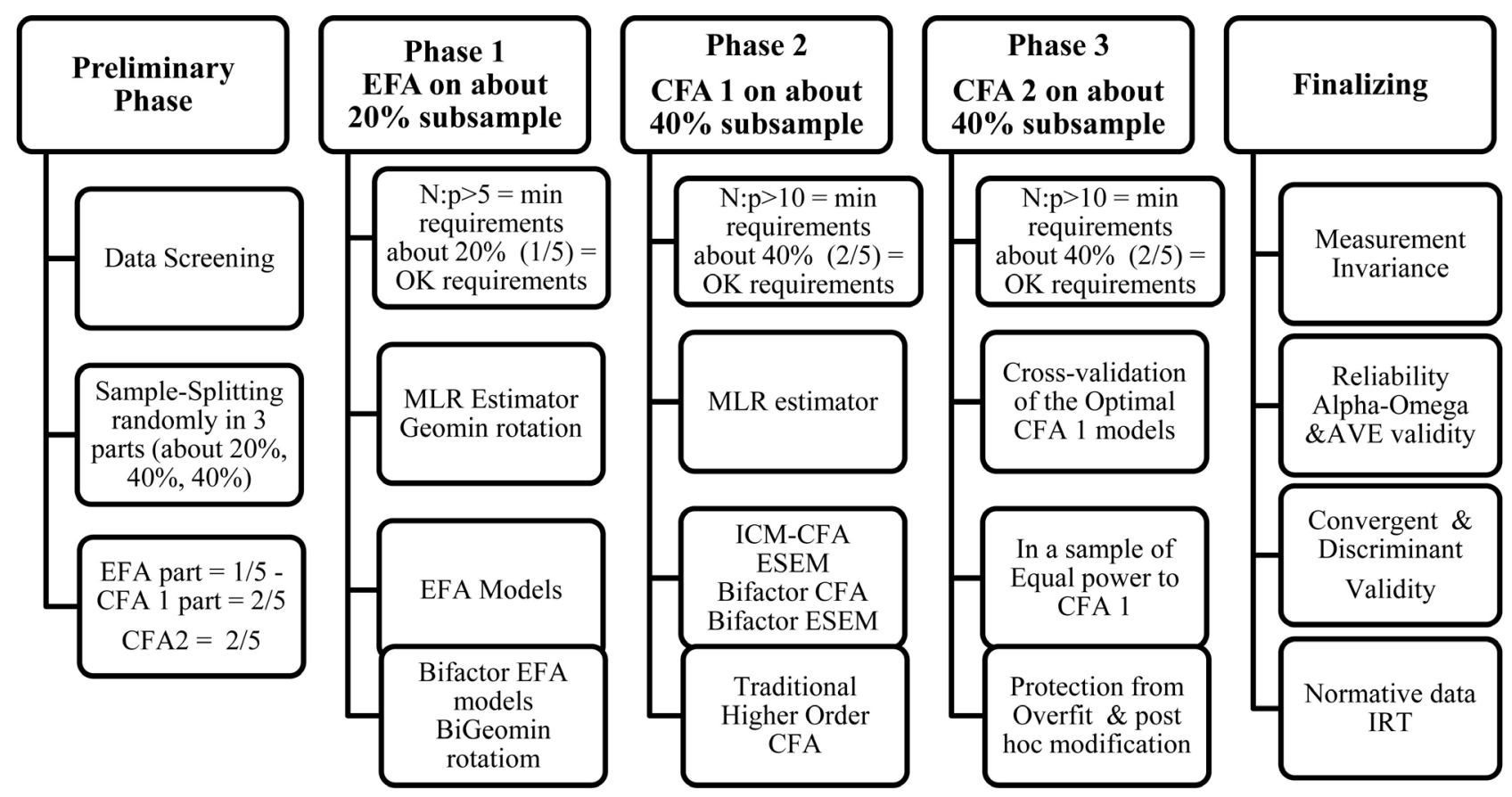

Figure 6. The 3-faced construct validation method. 
sample is randomly split into three parts $(20 \%, 40 \%$, and $40 \%)$ keeping the N:p ratio threshold for the EFA to 5:1, preferably 10:1 and for CFA to 10:1, preferably 20:1. The first $20 \%$ is used for MLR EFA. Multiple structures are tested along with a Bifactor EFA model. Regarding sample power, in all three samples caution is needed to be far beyond the suggested threshold of 5 to10 cases for each observed variable (Singh et al., 2016) and even the stricter 20 cases for each observed variable (Schumacker \& Lomax, 2015).

The second $40 \%$ is used for an explorative CFA (CFA 1) to test a minimum of the following alternative models: a single-factor ICM-CFA, a multifactor ICM-CFA with correlated and uncorrelated factors and their ESEM counterparts. Other theory-driven models to be tested include a Bifactor CFA model, a Bifactor ESEM model and a Higher-order CFA (if applicable). Next, the third $40 \%$ is used for a crosscheck CFA (CFA 2). This second CFA is intended to verify the optimal model (or competing optimal models) emerged in the CFA 1 in a different subsample of equal power to the CFA 1 subsample (both $40 \%$ ). If the CFA 2 fails to revalidate the optimal CFA 1 model, then the second best model is crosschecked etc. Measurement invariance using the cross-validated model as a baseline model is the final phase of the method. Note that, actually, the lesson to take home is not the exact percentages to split a sample but if the cases to indicators ratios are above the specified levels these are the minimum conditions to carry out the method. Thus, the sample can be divided into five parts and these are the adequate conditions to carry out the method. One part can be used for the EFA and the four parts for the two CFAs (2 parts for each). This would result in a sample $\mathrm{x}$ for EFA and $2 \mathrm{x}$ for each CFA as SEM requires large samples. If the sample is not adequate to be split in three and the structure of the validated instrument is known then the sample can be halved to carry out two CFAs as a protection against overfitting. However, the rules setting the minimum and adequate conditions must be followed. For an unknown structure EFA must be carried out in the first halve and a CFA must follow in the second halve, however in this case the solution is not protected against ovefitting. The study of a known structure must be designed in a way that at least two CFAs can be carried out after halving the sample.

The validation procedure is also suggested to include the following, in line with the general empirical method adopted for evaluating the psychometric properties of measurement instruments: 1) Reliability analysis using Cronbach's alpha, Omega Total coefficient and AVE-based construct validity, 2) Correlation Analysis to Examine Convergent and Discriminant Validity, 3) Normative Data, 4) Item response theory (IRT). The entire sample is suggested to be used for the above analyses, but alpha could be also calculated for the subsamples too if desired (DeVellis, 2017).

More specifically, reliability and validity are evaluated in the entire sample using the following measures; 1$)$ Cronbach's alpha ( $\alpha$; Cronbach, 1951) to examine internal consistency of the responses. Alpha values above .70 are generally acceptable (Hair et al., 2010), and above .80 adequate (Kline, 2000; Nunnally \& 
Berstein, 1994); 2) Omega Total coefficient ( $\omega$ total; McDonald, 1999; Werts, Linn, \& Jöreskog, 1974). Omega corresponds either to variance accounted by all factors or by each latent factor separately (Brunner et al., 2012). For omega a, value of .70 or greater is acceptable (Hair et al., 2010); 3) Average Variance Extracted (AVE; Fornell \& Larcker, 1981) to evaluate convergent validity. Malhotra $\&$ Dash (2011) comment that $\omega$ alone is weak, potentially allowing an error variance as high as $50 \%$. Therefore, AVE in combination with $\omega$ coefficient offers a more conservative estimation of convergent validity (Malhotra \& Dash, 2011). The threshold for AVE is .50 (Fornell \& Larcker, 1981; Hair et al., 2010).

Regarding normative data, it is included along with the means and ranges of the instrument dimensions. Means are not informative of individual scores, given the non-normality of the data (Crawford \& Henry, 2004). Therefore, scores are converted to percentiles. Finally, Item response theory (IRT) is carried out during the construction, analysis, scoring, and comparison of measurement instruments (questionnaires or ability tests) intended to measure an unobservable characteristics of the respondents (Binary response models: 1PL, 2PL, 3PL; Categorical response models: GRM, NRM, PCM, RSM; Multiple IRT models combined: Hybrid).

\section{Conclusion}

In conclusion, the " 3 -faced construct validation method" is a routine indented for establishing the validity and reliability of an existing scale when it is adapted in a different cultural context (not including the translation part). However, the routine can also be used for the initial validation of a newly developed instrument or for testing the measurement model in a SEM study. Empirical applications of the method were carried out by Kyriazos et al. (2018a, 2018b, 2018c, 2018d, 2018e).

Sample-splitting (Guadagnoli \& Velicer, 1988; MacCallum, Browne \& Sugawara, 1996) is generally an acknowledged cross-validation method (Byrne, 2012; Brown, 2015). Similar approaches to the " 3 -faced construct validation method" were also proposed by Brown (2015), by Singh et al. (2016), and by Muthén \& Muthén (2009a). Cross-validation is also used in SEM measurement models (see Byrne, 2012) or in logistic regression to cross-validate the results (Lomax \& Hahs-Vaughn, 2013).

The addition of the " 3 -faced construct validation method" in the empirical research of psychometrics regarding the adaption of measurement instruments in a different cultural context than the one they were initially developed is: 1) The rule of keeping the MLR EFA and Bifactor EFA N:p ratio above a minimum of 5 cases per variable and preferably 10 using $20 \%$ of the sample 2) The use of the rest $80 \%$ of the sample to carry out two "twin" CFAs, i.e. two CFAs in two subsamples of equal power $40 \%$ each (minimum requirements and adequate requirements respectively). The rule here is to keep the CFA $\mathrm{N}$ : $\mathrm{p}$ ratio above a minimum of 10 cases per variable and preferably 20 using $40 \%$ of the sample for 
each CFA. 3) The use of multiple methods in the first exploratory CFA and multiple models (ICM-CFA, ESEM, Bifactor CFA, Bifactor ESEM, and "traditional" Higher-order CFA when applicable. What to keep in mind is not the exact percentage to split a sample. Again it should be emphasized that the central message conveyed is if the cases to indicators ratios are above at the specified levels (minimum conditions) then the sample can be divided into five parts (adequate conditions). One part can be used for the EFA and the four parts for the two CFAs (2 parts for each). This would result in a sample $\mathrm{x}$ for EFA and $2 \mathrm{x}$ for each CFA as SEM requires large samples. The method is a protection against overfitting but it requires careful planning and a large sample.

\section{Conflicts of Interest}

The authors declare no conflicts of interest regarding the publication of this paper.

\section{References}

Allison, P. D. (2002). Missing Data. Thousand Oaks, CA: Sage. https://doi.org/10.4135/9781412985079

Allison, P. D. (2003). Missing Data Techniques for Structural Equation Modeling. Journal of Abnormal Psychology, 112, 545-557. https://doi.org/10.1037/0021-843X.112.4.545

Anderson, J. C., \& Gerbing, D. W. (1988). Structural Equation Modeling in Practice: A Review and Recommended Two-Step Approach. Psychological Bulletin, 103, 411-423. https://doi.org/10.1037/0033-2909.103.3.411

Asparouhov, T., \& Muthén, B. (2009). Exploratory Structural Equation Modeling. Structural Equation Modeling, 16, 397-438. https://doi.org/10.1080/10705510903008204

Bentler, P. M. (1995). EQS Structural Equations Program Manual. Encino, CA: Multivariate Software.

Bentler, P. M., \& Chou, C. P. (1987). Practical Issues in Structural Modeling. Sociological Methods \& Research, 16, 78-117. https://doi.org/10.1177/0049124187016001004

Bentler, P. M., \& Wu, E. J. C. (2002). EQS 6 for Windows Guide. Encino, CA: Multivariate Software.

Bentler, P. M., \& Yuan, K. H. (1999). Structural Equation Modeling with Small Samples: Test Statistics. Multivariate Behavioral Research, 34, 181-197. https://doi.org/10.1207/S15327906Mb340203

Bollen, K. A. (1989). A New Incremental Fit Index for General Structural Equation Models. Sociological Methods \& Research, 17, 303-316. https://doi.org/10.1177/0049124189017003004

Bollen, K. A. (2002). Latent Variables in Psychology and the Social Sciences. Annual Review of Psychology, 53, 605-634. https://doi.org/10.1146/annurev.psych.53.100901.135239

Brown, T. A. (2015). Confirmatory Factor Analysis for Applied Research (2nd ed.). New York: Guilford Publications.

Browne, M. W., \& Arminger, G. (1995). Specification and Estimation of Mean- and Covariance-Structure Models. In Handbook of Statistical Modeling for the Social and Behavioral Sciences (pp. 185-249). Boston, MA: Springer. https://doi.org/10.1007/978-1-4899-1292-3_4 
Brunner, M., Nagy, G., \& Wilhelm, O. (2012). A Tutorial on Hierarchically Structured Constructs. Journal of Personality, 80, 796-846.

https://doi.org/10.1111/j.1467-6494.2011.00749.x

Byrne, B. M. (2006). Structural Equation Modeling with EQS: Basic Concepts, Applications, and Programming (2nd ed.). Mahwah, NJ: Lawrence Erlbaum Associates, Inc.

Byrne, B. M. (2012). Structural Equation Modeling with Mplus: Basic Concepts, Applications, and Programming. London: Routledge.

Byrne, B. M., Shavelson, R., \& Muthen, B. (1989) Testing for the Equivalence of Factor Covariance and Mean Structures: The Issue of Partial Measurement Invariance. Psychological Bulletin, 105, 456-466. https://doi.org/10.1037/0033-2909.105.3.456

Cattell, R. B. (1978). Scientific Use of Factor Analysis in Behavioral and Life Sciences. New York: Plenum Press. https://doi.org/10.1007/978-1-4684-2262-7

Chen, F. F. (2007). Sensitivity of Goodness of Fit Indexes to Lack of Measurement Invariance. Structural Equation Modeling, 14, 464-504. https://doi.org/10.1080/10705510701301834

Cheung, G. W., \& Rensvold, R. B. (2002). Evaluating Goodness-of-Fit Indexes for Testing Measurement Invariance. Structural Equation Modeling, 9, 233-255. https://doi.org/10.1207/S15328007SEM0902_5

Chou, C. P., \& Bentler, P. M. (1990). Model Modification in Covariance Structure Modeling: A Comparison among Likelihood Ratio, Lagrange Multiplier, and Wald Tests. Multivariate Behavioral Research, 25, 115-136. https://doi.org/10.1207/s15327906mbr2501_13

Clark, S. L., Miller, M. W., Wolf, E. J., \& Harrington, K. M. (2013). Sample Size Requirements for Structural Equation Models: An Evaluation of Power, Bias, and Solution Propriety. Educational and Psychological Measurement, 73, 913-934.

Cliff, N. (1983). Some Cautions Concerning the Application of Causal Modeling Methods. Multivariate Behavioral Research, 18, 115-126. https://doi.org/10.1207/s15327906mbr1801_7

Comrey, A. L. (1988). Factor-Analytic Methods of Scale Development in Personality and Clinical Psychology. Journal of Consulting and Clinical Psychology, 56, 754. https://doi.org/10.1037/0022-006X.56.5.754

Comrey, A. L., \& Lee, H. B. (1973). A First Course in Factor Analysis. New York, NY: Academic Press.

Comrey, A. L., \& Lee, H. B. (1992). A First Course in Factor Analysis. Hillsdale, NJ: Lawrence Eribaum Associates.

Comrey, A. L., \& Lee, H. B. (1992). Interpretation and Application of Factor Analytic Results. In A. L. Comrey, \& H. B. Lee (Eds.), A First Course in Factor Analysis (p. 2). Hillsdale, NJ: Lawrence Eribaum Associates.

Costello, A. B., \& Osborne, J. W. (2005). Best Practices in Exploratory Factor Analysis: Four Recommendations for Getting the Most from Your Analysis. Practical Assessment, Research \& Evaluation, 10,1-9.

Crawford, J. R., \& Henry, J. D. (2004). The Positive and Negative Affect Schedule (PANAS): Construct Validity, Measurement Properties and Normative Data in a Large Non-Clinical Sample. British Journal of Clinical Psychology, 43, 245-265. https://doi.org/10.1348/0144665031752934

Crocker, L., \& Algina, J. (1986). Introduction to Classical and Modern Test Theory. New York, NY: Holt, Rinehart and Winston. 
Cronbach, L. J. (1951). Coefficient Alpha and the Internal Structure of Tests. Psychometrika, 16, 297-334. https://doi.org/10.1007/BF02310555

Cronbach, L. J., \& Meehl, P. E. (1955). Construct Validity in Psychological Tests. Psychological Bulletin, 52, 281-302. https://doi.org/10.1037/h0040957

Csikszentmihalyi, M. (2000). Happiness, Flow, and Economic Equality.

Csikszentmihalyi, M., Larson, R., \& Prescott, S. (1977). The Ecology of Adolescent Activity and Experience. Journal of Youth and Adolescence, 6, 281-294. https://doi.org/10.1007/BF02138940

Cudeck, R., \& Browne, M. W. (1983). Cross-Validation of Covariance Structures. Multivariate Behavioral Research, 18, 147-167. https://doi.org/10.1207/s15327906mbr1802_2

Cudeck, R., MacCallum, R. C., Millsap, R. E., \& Meredith, W. (2007). Factor Analysis at 100: Historical Developments and Future Directions.

DeVellis, R. F. (2017). Scale Development: Theory and Applications (4th ed.). Thousand Oaks, CA: Sage.

Ding, L., Velicer, W. F., \& Harlow, L. L. (1995). Effects of Estimation Methods, Number of Indicators per Factor, and Improper Solutions on Structural Equation Modeling Fit Indices. Structural Equation Modeling: A Multidisciplinary Journal, 2, 119-143. https://doi.org/10.1080/10705519509540000

Doornik, J. A., \& Hansen, H. (2008). An Omnibus Test for Univariate and Multivariate Normality. Oxford Bulletin of Economics and Statistics, 70, 927-939. https://doi.org/10.1111/j.1468-0084.2008.00537.x

Enders, C. K. (2010). Applied Missing Data Analysis. New York, NY: Guilford Press.

Epskamp, S., Rhemtulla, M., \& Borsboom, D. (2017). Generalized Network Pschometrics: Combining Network and Latent Variable Models. Psychometrika, 82, 904-927. https://doi.org/10.1007/s11336-017-9557-x

Fabrigar, L. R., \& Wegener, D. T. (2012). Exploratory Factor Analysis. New York, NY: Oxford University Press, Inc.

Fabrigar, L. R., Wegener, D. T., MacCallum, R. C., \& Strahan, E. J. (1999). Evaluating the Use of Exploratory Factor Analysis in Psychological Research. Psychological Methods, 4, 272-299. https://doi.org/10.1037/1082-989X.4.3.272

Fornell, C., \& Larcker, D. F. (1981). Structural Equation Models with Unobservable Variables and Measurement Error: Algebra and Statistics. Journal of Marketing Research, 382-388. https://doi.org/10.2307/3150980

Garver, M. S., \& Mentzer, J. T. (1999). Logistics Research Methods: Employing Structural Equation Modeling to Test for Construct Validity. Journal of Business Logistics, 20, 33-57.

Gorsuch, R. L. (1983). Factor Analysis (2nd ed.). Hillsdale, NJ: LEA.

Green, S. B., \& Babyak, M. A. (1997). Control of Type I Errors with Multiple Tests of Constraints in Structural Equation Modeling. Multivariate Behavioral Research, 32, 39-51. https://doi.org/10.1207/s15327906mbr3201_2

Green, S. B., Thompson, M. S., \& Poirier, J. (1999). Exploratory Analyses to Improve Model Fit: Errors Due to Misspecification and a Strategy to Reduce Their Occurrence. Structural Equation Modeling: A Multidisciplinary Journal, 6, 113-126. https://doi.org/10.1080/10705519909540122

Green, S. B., Thompson, M. S., \& Poirier, J. (2001). An Adjusted Bonferroni Method for Elimination of Parameters in Specification Addition Searches. Structural Equation Modeling, 8, 18-39. 
Guadagnoli, E., \& Velicer, W. F. (1988). Relation of Sample Size to the Stability of Component Patterns. Psychological Bulletin, 103, 265-275.

https://doi.org/10.1037/0033-2909.103.2.265

Hair, J., Black, W., Babin, B., \& Anderson, R. (2010). Multivariate Data Analysis (7th ed.). Upper Saddle River, NJ: Prentice-Hall, Inc.

Hammer, J. H., \& Toland, M. D. (2016). Bifactor Analysis in Mplus. http://sites.education.uky.edu/apslab/upcoming-events/

Harman, H. H. (1976). Modern Factor Analysis. Chicago, IL: University of Chicago Press.

Hayduk, L. A. (1987). Structural Equation Modeling with LISREL: Essentials and Advances. Baltimore, MD: JHU Press.

Henze, N., \& Zirkler, B. (1990). A Class of Invariant Consistent Tests for Multivariate Normality. Communications in Statistics-Theory and Methods, 19, 3595-3617. https://doi.org/10.1080/03610929008830400

Hill, C. E., Thompson, B. J., \& Williams, E. N. (1997). A Guide to Conducting Consensual Qualitative Research. The Counseling Psychologist, 25, 517-572. https://doi.org/10.1177/0011000097254001

Hoe, S. L. (2008). Issues and Procedures in Adopting Structural Equation Modeling Technique. Journal of Applied Quantitative Methods, 3, 76-83.

Hoelter, J. W. (1983). The Analysis of Covariance Structures: Goodness-of-Fit Indices. Sociological Methods \& Research, 11, 325-344. https://doi.org/10.1177/0049124183011003003

Holzinger, K. J. (1937). Student Manual of Factor Analysis.

Holzinger, K. J., \& Swineford, F. (1937). The Bi-Factor Method. Psychometrika, 2, 41-54. https://doi.org/10.1007/BF02287965

Horn, J. L., McArdle, J. J., \& Mason, R. (1983). When Is Invariance Not Invarient: A Practical Scientist's Look at the Ethereal Concept of Factor Invariance. Southern Psychologist, 1, 179-188.

Howard, J., Gagné, M., Morin, A. J., \& Van den Broeck, A. (2016). Motivation Profiles at Work: A Self-Determination Theory Approach. Journal of Vocational Behavior, 95, 74-89. https://doi.org/10.1016/j.jvb.2016.07.004

Hu, L. T., \& Bentler, P. M. (1999). Cutoff Criteria for Fit Indexes in Covariance Structure Analysis: Conventional Criteria versus New Alternatives. Structural Equation Modeling: A Multidisciplinary Journal, 6, 1-55. https://doi.org/10.1080/10705519909540118

Hu, L. T., Bentler, P. M., \& Kano, Y. (1992). Can Test Statistics in Covariance Structure Analysis Be Trusted? Psychological Bulletin, 112, 351-362. https://doi.org/10.1037/0033-2909.112.2.351

Jaccard, J., Jaccard, J., \& Wan, C. K. (1996). LISREL Approaches to Interaction Effects in Multiple Regression (No. 114). London: Sage. https://doi.org/10.4135/9781412984782

Jennrich, R. I., \& Bentler, P. M. (2011). Exploratory Bi-Factor Analysis. Psychometrika, 76, 537-549. https://doi.org/10.1007/s11336-011-9218-4

Jennrich, R. I., \& Bentler, P. M. (2012). Exploratory Bi-Factor Analysis: The Oblique Case. Psychometrika, 77, 442-454. https://doi.org/10.1007/s11336-012-9269-1

Joreskog, K. G., Sorbom, D., \& Magidson, J. (1979). Advances in Factor Analysis and Structural Equation Models.

Joshanloo, M., \& Jovanović, V. (2017). The Factor Structure of the Mental Health Continuum-Short Form (MHC-SF) in Serbia: An Evaluation Using Exploratory Structural Equation Modeling. Journal of Mental Health, 26, 510-515. 
https://doi.org/10.1080/09638237.2016.1222058

Joshanloo, M., Jose, P. E., \& Kielpikowski, M. (2017). The Value of Exploratory Structural Equation Modeling in Identifying Factor Overlap in the Mental Health Continuum-Short Form (MHC-SF): A Study with a New Zealand Sample. Journal of Happiness Studies, 18, 1061-1074. https://doi.org/10.1007/s10902-016-9767-4

Kahn, J. H. (2006). Factor Analysis in Counseling Psychology Research, Training, and Practice: Principles, Advances, and Applications. The Counseling Psychologist, 34, 684-718. https://doi.org/10.1177/0011000006286347

Karson, M. (2007). Diagnostic Validity. In N. J. Salkind (Ed.), Encyclopedia of Measurement and Statistics (pp. 254-248). Thousand Oaks, CA: Sage.

Kelloway, E. K. (2015). Using Mplus for Structural Equation Modeling.

Kline, P. (2000). Handbook of Psychological Testing. London: Routledge.

Kline, R. B. (2009). Becoming a Behavioral Science Researcher: A Guide Toproducing Research That Matters. New York, NY: Guilford Publications.

Kline, R. B. (2013). Beyond Significance Testing: Statistics Reform in the Behavioral Sciences (2nd ed.). Washington DC: American Psychological Association. https://doi.org/10.1037/14136-000

Kline, R. B. (2016). Principles and Practice of Structural Equation Modeling (4th ed.). New York, NY: Guilford Publications.

Kyriazos, T. A., Stalikas, A., Prassa, K., \& Yotsidi, V. (2018a). Can the Depression Anxiety Stress Scales Short Be Shorter? Factor Structure and Measurement Invariance of DASS-21 and DASS-9 in a Greek, Non-Clinical Sample. Psychology, 9, 1095-1127.

Kyriazos, T. A., Stalikas, A., Prassa, K., \& Yotsidi, V. (2018b). A 3-Faced Construct Validation and a Bifactor Subjective Well-Being Model Using the Scale of Positive and Negative Experience, Greek Version. Psychology, 9, 1143-1175.

Kyriazos, T. A., Stalikas, A., Prassa, K., Galanakis, M., Flora, K., \& Chatzilia, V. (2018c). The Flow Short Scale (FSS) Dimensionality and What MIMIC Shows on Heterogeneity and Invariance. Psychology, 9, 1357-1382.

Kyriazos, T. A., Stalikas, A., Prassa, K., Yotsidi, V., Galanakis, M., \& Pezirkianidis, C. (2018d). Validation of the Flourishing Scale (FS), Greek Version and Evaluation of Two Well-Being Models. Psychology, 9, 1789-1813.

Kyriazos, T. A., Stalikas, A., Prassa, K., Galanakis, M., Yotsidi, V., \& Lakioti, L. (2018e). Psychometric Evidence and Invariance of the Brief Resilience Scale (BRS) in Greek Adults. Modeling Distinctiveness of Resilience from Depression and Stress. Psychology, 9.

Little, R. J., \& Rubin, D. B. (2002). Bayes and Multiple Imputation. In R. J. A. Little, \& D. B. Rubin (Eds.), Statistical Analysis with Missing Data (pp. 200-220). Hoboken: Wiley.

Lomax, R. G., \& Hahs-Vaughn, D. L. (2013). An Introduction to Statistical Concepts. Abingdon-on-Thames: Routledge.

MacCallum, R. C. (1986). Specification Searches in Covariance Structure Modeling. Psychological Bulletin, 100, 107-120. https://doi.org/10.1037/0033-2909.100.1.107

MacCallum, R. C., \& Austin, J. T. (2000). Applications of Structural Equation Modeling in Psychological Research. Annual Review of Psychology, 51, 201-226.

https://doi.org/10.1146/annurev.psych.51.1.201

MacCallum, R. C., Browne, M. W., \& Sugawara, H. M. (1996). Power Analysis and Determination of Sample Size for Covariance Structure Modeling. Psychological Methods, 1, 130-149. https://doi.org/10.1037/1082-989X.1.2.130 
MacCallum, R. C., Roznowski, M., \& Necowitz, L. B. (1992). Model Modifications in Covariance Structure Analysis: The Problem of Capitalization on Chance. Psychological Bulletin, 111, 490-504. https://doi.org/10.1037/0033-2909.111.3.490

MacCallum, R. C., Roznowski, M., Mar, C. M., \& Reith, J. V. (1994). Alternative Strategies for Cross-Validation of Covariance Structure Models. Multivariate Behavioral Research, 29, 1-32. https://doi.org/10.1207/s15327906mbr2901_1

MacCallum, R. C., Wegener, D. T., Uchino, B. N., \& Fabrigar, L. R. (1993). The Problem of Equivalent Models in Applications of Covariance Structure Analysis. Psychological Bulletin, 114, 185-199. https://doi.org/10.1037/0033-2909.114.1.185

MacCallum, R. C., Widaman, K. F., Zhang, S., \& Hong, S. (1999). Sample Size in Factor Analysis. Psychological Methods, 4, 84-99. https://doi.org/10.1037/1082-989X.4.1.84

Malhotra, N. K., \& Dash, S. (2011). Marketing Research: An Applied Orientation (6th ed.). London: Pearson Education.

Mardia, K. V. (1970). Measures of Multivariate Skewness and Kurtosis with Applications. Biometrika, 57, 519-530. https://doi.org/10.1093/biomet/57.3.519

Marsh, H. W., Ludtke, O., Muthen, B., Asparouhov, T., Morin, A. J. S., \& Trautwein, U. (2010). A New Look at the Big Five Factor Structure through Exploratory Structural Equation Modeling. Psychological Assessment, 22, 471-491. https://doi.org/10.1037/a0019227

Marsh, H. W., Muthen, B., Asparouhov, T., Ludtke, O., Robitzsch, A. et al. (2009). Exploratory Structural Equation Modeling, Integrating CFA and EFA: Application to Students' Evaluations of University Teaching. Structural Equation Modeling, 16, 439-476. https://doi.org/10.1080/10705510903008220

Marsh, H., Morin, A., Parker, P., \& Kaur, G. (2014). Exploratory Structural Equation Modeling: An Integration of the Best Features of Exploratory and Confirmatory Factor Analysis. Annual Review of Clinical Psychology, 10, 85-110. https://doi.org/10.1146/annurev-clinpsy-032813-153700

Massey Jr., F. J. (1951). The Kolmogorov-Smirnov Test for Goodness of Fit. Journal of the American Statistical Association, 46, 68-78. https://doi.org/10.1080/01621459.1951.10500769

McCall, C. H. (1982). Sampling and Statistics Handbook for Research. Iowa State Pr.

McDonald, R. P. (1985). Factor Analysis and Related Methods. Hillsdale, NJ: Erlbaum.

McDonald, R. P. (1999). Test Theory: A Unified Treatment. Hillsdale, NJ: Erlbaum.

McQuitty, S. (2004). Statistical Power and Structural Equation Models in Business Research. Journal of Business Research, 57, 175-183. https://doi.org/10.1016/S0148-2963(01)00301-0

Messick, S. (1995). Validity of Psychological Assessment: Validation of Inferences from Persons' Responses and Performances as Scientific Inquiry into Score Meaning. American Psychologist, 50, 741-749. https://doi.org/10.1037/0003-066X.50.9.741

Milfont, T. L., \& Fischer, R. (2010). Testing Measurement Invariance across Groups: Applications in Cross-Cultural Research. International Journal of Psychological Research, 3, 111-130. https://doi.org/10.21500/20112084.857

Morin, A. J. S., Arens, A., \& Marsh, H. (2016). A Bifactor Exploratory Structural Equation Modeling Framework for the Identification of Distinct Sources of Construct-Relevant Psychometric Multidimensionality. Structural Equation Modeling, 23, 116-139. https://doi.org/10.1080/10705511.2014.961800

Morin, A. J. S., Marsh, H., \& Nagengast, B. (2013). Exploratory Structural Equation Modeling: an Introduction. In G. R. Hancock, \& R. O. Mueller (Eds.), Structural Equation 
Modeling: A Second Course (2nd ed., pp. 395-436). Greenwich, CT: IAP.

Muthen, B., \& Asparouhov, T. (2002). Latent Variable Analysis with Categorical Outcomes: Multiple-Group and Growth Modeling in Mplus. Mplus Web Notes, 4, 1-22.

Muthén, B., \& Muthén, B. O. (2009a). Statistical Analysis with Latent Variables. New York, NY: Wiley.

Muthén, L. K., \& Muthén, B. O. (2009b). Mplus Short Courses, Topic 1: Exploratory Factor Analysis, Confirmatory Factor Analysis, and Structural Equation Modeling for Continuous Outcomes. Los Angeles, CA: Muthén \& Muthén.

http://www.statmodel.com

Muthen, L. K., \& Muthen, B. O. (2012). Mplus Version 7 User's Guide. Los Angeles, CA: Muthén \& Muthén.

Nunnally, J. C., \& Bernstein, I. H. (1994). Psychometric Theory(3rd ed.). New York, NY: McGraw-Hill.

Pedhazur, E. J., \& Schmelkin, L. P. (1991). Measurement, Design, and Analysis: An Integrated Analysis. Journal of Econometrics, 22, 229-243.

Porter, R. D., \& Fabrigar, L. R. (2007). Factor Analysis. In N. J. Salkind (Ed.), Encyclopedia of Measurement and Statistics (pp. 341-345). Thousand Oaks, CA: Sage.

Preacher, K. J., MacCallum, R. C., Kiecolt-Glaser, J. K., Atkinson, C., Malarkey, W. B., \& Glaser, R. (2003). Chronic Stress and Age-Related Increases in the Proinflammatory Cytokine IL-6. Proceedings of the National Academy of Sciences, 100, 9090-9095. https://doi.org/10.1073/pnas.1531903100

Reise, S. P. (2012). The Rediscovery of Bifactor Measurement Models. Multivariate Behavioral Research, 47, 667-696. https://doi.org/10.1080/00273171.2012.715555

Reise, S. P., Morizot, J., \& Hays, R. D. (2007). The Role of the Bifactor Model in ResolvingDimensionality Issues in Health Outcomes Measures. Quality of Life Research, 16, 19-31. https://doi.org/10.1007/s11136-007-9183-7

Revelle, W. (2018). Using the Psych Package to Generate and Test Structural Models.

Rosenthal, R., \& Rosnow, R. L. (1984). Applying Hamlet's Question to the Ethical Conduct of Research: A Conceptual Addendum. American Psychologist, 39, 561-563. https://doi.org/10.1037/0003-066X.39.5.561

Russell, D. W. (2002). In Search of Underlying Dimensions: The Use (and Abuse) of Factor Analysis in Personality and Social Psychology Bulletin. Personality and Social Psychology Bulletin, 28, 1629-1646. https://doi.org/10.1177/014616702237645

Satorra, A., \& Bentler, P. M. (2010). Ensuring Positiveness of the Scaled Difference Chi-Square Test Statistic. Psychometrika, 75, 243-248. https://doi.org/10.1007/s11336-009-9135-y

Satorra, A., \& Saris, W. E. (1985). Power of the Likelihood Ratio Test in Covariance Structure Analysis. Psychometrika, 50, 83-90. https://doi.org/10.1007/BF02294150

Savalei, V. (2014). Understanding Robust Corrections in Structural Equation Modeling. Structural Equation Modeling: A Multidisciplinary Journal, 21, 149-160. https://doi.org/10.1080/10705511.2013.824793

Sawilowsky, S. S. (2007). Construct Validity. In N. J. Salkind (Ed.), Encyclopedia of Measurement and Statistics (pp. 178-180). Thousand Oaks, CA: Sage.

Schafer, J. L., \& Graham, J. W. (2002). Missing Data: Our View of the State of the Art. Psychological Methods, 7, 147-177. https://doi.org/10.1037/1082-989X.7.2.147

Schumacker, R. E., \& Lomax, R. G. (2015). A Beginner's Guide to Structural Equation Modeling (4th ed.). New York, NY: Routledge. 
Silvia, E. S. M., \& MacCallum, R. C. (1988). Some Factors Affecting the Success of Specification Searches in Covariance Structure Modeling. Multivariate Behavioral Research, 23, 297-326. https://doi.org/10.1207/s15327906mbr2303_2

Singh, K., Junnarkar, M., \& Kaur, J. (2016). Measures of Positive Psychology, Development and Validation. Berlin: Springer. https://doi.org/10.1007/978-81-322-3631-3

Sivo, S. A., Fan, X., Witta, E. L., \& Willse, J. T. (2006). The Search for “Optimal” Cutoff Properties: Fit Index Criteria in Structural Equation Modeling. The Journal of Experimental Education, 74, 267-288. https://doi.org/10.3200/JEXE.74.3.267-288

Spearman, C. (1904). General Intelligence, Objectively Determined and Measured. The American Journal of Psychology, 15, 201-292. https://doi.org/10.2307/1412107

Spearman, C. (1927). The Abilities of Man. New York: Macmillan

Steiger, J. H., \& Lind, J. C. (1980). Statistically-Based Tests for the Number of Common Factors.

Tabachnick, B. G., \& Fidell, L. S. (2013). Using Multivariate Statistics (6th ed.) Boston, MA: Allyn \& Bacon/Pearson Education.

Thompson, B. (1994). The Pivotal Role of Replication in Psychological Research: Empirically Evaluating the Replicability of Sample Results. Journal of Personality, 62, 157-176. https://doi.org/10.1111/j.1467-6494.1994.tb00289.x

Thompson, B. (2000). Ten Commandments of Structural Equation Modeling. In L. Grimm, \& P. Yarnold (Eds.), Reading and Understanding More Multivariate Statistics (pp. 261-284). Washington DC: American Psychological Association.

Thompson, B. (2004). Exploratory and Confirmatory Factor Analysis: Understanding Concepts and Applications. Washington DC: American Psychological Association.

Thompson, B. (2013). Overview of Traditional/Classical Statistical Approaches. In T. Little (Ed.), The Oxford Handbook of Quantitative Methods (Vol. 1-2, pp. 7-25). New York, NY: Oxford University Press. https://doi.org/10.1093/oxfordhb/9780199934898.013.0002

Thompson, B., \& Vacha-Haase, T. (2000). Psychometrics Is Data Metrics: The Test Is Notreliable. Educational and Psychological Measurement, 60, 174-195. https://doi.org/10.1177/0013164400602002

Thurstone, L. L. (1935). The Vectors of Mind: Multiple-Factor Analysis for the Isolation of Primary Traits.

Thurstone, L. L. (1947). Multiple Factor Analysis. Chicago: University of Chicago Press.

Timmons, A. C. (2010). Establishing Factorial Invariance for Multiple-Group Confirmatory Factor Analysis. KU Guide No. 22.1. http://www.quant.ku.edu

Tinsley, H. E., \& Tinsley, D. J. (1987). Uses of Factor Analysis in Counseling Psychology Research. Journal of Counseling Psychology, 34, 414-424. https://doi.org/10.1037/0022-0167.34.4.414

Wang, J., \& Wang, X. (2012). Structural Equation Modeling: Applications Using Mplus. Hoboken, NJ: John Wiley \& Sons. https://doi.org/10.1002/9781118356258

Werts, C. E., Linn, R. N., \& Jöreskog, K. G. (1974). Interclass Reliability Estimates: Testing Structural Assumptions. Educational \& Psychological Measurement, 34, 25-33. https://doi.org/10.1177/001316447403400104

Widaman, K. F., \& Reise, S. P. (1997). Exploring the Measurement Invariance of Psychological Instruments: Applications in the Substance Use Domain. In K. J. Bryant, M. Windle, \& S. G. West (Eds.), The Science of Prevention: Methodological Advances from Alcohol and Substance Abuse Research (pp. 281-324). Washington DC: American Psychological Association. 
Williams, B., Onsman, A., \& Brown, T. (2010). Exploratory Factor Analysis: A Five-Step Guide for Novices. Australasian Journal of Paramedicine, 8, 1-13.

Wolff, H. G., \& Preising, K. (2005). Exploring Item and Higher Order Factor Structure with the Schmid-Leiman Solution: Syntax Codes for SPSS and SAS. Behavior Research Methods, 37, 48-58. https://doi.org/10.3758/BF03206397

Zinbarg, R. E., Yovel, I., Revelle, W., \& McDonald, R. P. (2006). Estimating Generalizability to a Latent Variable Common to All of a Scale's Indicators: A Comparison of Estimators for $\omega \mathrm{h}$. Applied Psychological Measurement, 30, 121-144. https://doi.org/10.1177/0146621605278814

Zumbo, B. D., Gelin, M. N., \& Hubley, A. M. (2002). The Construction and Use of Psychologicaltests and Measures. In Encyclopedia of Life Support Systems (pp. 1-28). Oxford: Eolss Publishers. 